\title{
On colour vision
}

This content has been downloaded from IOPscience. Please scroll down to see the full text. 1907 Trans. Opt. Soc. 9107

(http://iopscience.iop.org/1475-4878/9/1/306)

View the table of contents for this issue, or go to the journal homepage for more

Download details:

IP Address: 142.66.3.42

This content was downloaded on 07/09/2015 at 13:52

Please note that terms and conditions apply. 
ON COLOUR VISION.

By Prof. G. J. Burch, M.A., D.Sc., F.R.S.

Lecture delivered before the Optrcal Society on Aprul ith, 1908.

Science has become so vast a subject in these days that no self-respecting man, even in one branch of science, will undertake to know all the elementary parts of it. The things that we really do interest ourselves about with regard to our neighbour's hobby are his latest discoveries. And for this reason I, personally, always feel thankful to a lecturer who will condescend to spend the first fire minutes in going over the $A B C$ of what he is going to talk about. Of course, I ought to have learnt it all at school, and very likely I did, but it helps me to understand and to enjor a lecture if the lecturer will, at the beginning, treat me as if I knew nothing at all about the subject. Therefore, I anı going to ask rour indulgence while I remind rou of the fundamental facts of "Colour Vision."

First of all, I would ask to have put upon the screen a diagram of the eye. The eye, as you know, is like a photographic camera; it has a compound lens, consisting of the cornea, the aqueous humour, the lens itself, and the ritreous humour. It is provided with what is, in point of fact, the original of the iris diaphragmnamely, the pupil. But the eye goes one better than the photographic camera, in that the adjustable stop it possesses is automatic, contracting of itself when the light is excessive, and expanding of itself when the light is not sufficient. Then, too, there are muscles attached to the lens, which, br their action, partly alter its shape and 
partly alter its position. In the case of fishes the focus is principally attained by altering the position of the lens. These muscles have the effect of focusing the image upon the sensitive surface, which is known as the retina. But whereas with a camera you have to put in a fresh plate, and when you have taken a photograph you take the plate out, and pour the developer upon it, and carry away the picture, in the case of the eye, the images are not fixed permanently, although they are fixed for a short time, upon the retina, but are telegraphed, as it were, through the optic nerve to the brain, where they undergo a process of sorting, and comparing, and arranging, and recording, by a somewhat capricious method of selection, until ther are stored up in the memory, to be brought out thence as we may bring out our photographic picture, when they are required, or sometimes when we can lay our hands upon them. So that, after all, the eye is very much like a photograplic camera.

But to-night I am concerned, not so much with the optical system of the eye, nor even with the microscopic construction of the retina, with its rods and cones, but with the functions of the retina. And there are one or two things about it which I should recall to your minds. First, there are two special points of peculiar and particular interest on the retina-the blind spot and the yellow spot. The point where the optic nerve goes into the eye constitutes the blind spot; because the optic nerve is no more capable of receiving a sensation than a telegraphic wire is capable of receiving a message. It merely transmits the sensation to the organ which makes you aware of it. The nerve itself is absolutely insensitive to light. There is another thing which gave me the greatest astonishment when I first learnt it. The nerve which transmits the images to the brain comes through from the back of the eye, and spreads out its branches all over the front of the sensitive surface that 
receives the picture. One would naturally suppose that the nerves would be at the back of the rods and cones. The latter receive the lightthey give the sensation-and one would expect that the nerve should lie behind the mechanisin for receiving the impulses of light. But no; it spreads over the front of it. The reason why this is so is bound up in the history of life upon this world, and we could not explain it without going into the long history of the way in which the sense of vision has developed. The nerve, then, comes through the eye, spreads over the inner surface of it, and from the organs at the ends of the tiniest branchlets of the ierve is the picture transmitted. And so it conies about that the part where the nerve fibres are bunched together in order to go through to the brain is absolutely blind. Of course, you know the simple experiment for demonstrating that. You take the cover of a book, you lay upon it two little chips of white paper, the smaller the better, side by side, about three inches apart, and hold it about a foot from rour eyes. Now shut the right eye, and look at the right-hand piece of paper, or shut the left eye, and look at the left-hand piece. By moving the book-cover a little nearer, or a little farther off, you will find the position where the spot you are not looking at vanishes. If you pass your finger round it, you can see your finger going all the way round, but you cannot see the spot, because when your erve is in that position, the image of one of the spots falls upon the nerve where it goes through the retina from the front to the back, and that part is blind. It is so far blind that rou may put two lighted candles side by side, and look at one of them with one eve shut, and when you get them at the proper distance the other flame will disappear. You may, if you have sufficient command of your muscles, place a candle side by side with an arc lamp, and the are lamp will disappear. Or you may even-still if you have sufficient command of your muscles, and with 
the aid of a piece of looking-glass-perform the same experiment with the image of the sun itself, and you will not see the sun, because that part of your eye is absolutely stone-blind.

The other interesting part of the retina is the yellow spot. The retina there is thinner than it is anywhere else. It is the most sensitive, and the most accurate part. In point of fact, there is no definition worth speaking of in any other part of your eye. You cannot read with any other part but the yellow spot. It does all the reading, and is consequently generally in a state of chronic fatigue.

The special sensitiveness and the peculiar properties of the yellow spot may be demonstrated by the following experiment. Take a flat bottle -a medicine-bottle will do very well-and fill it with a solution of chrome alum. You must find out the proper strength by trial. The colour of the solution is a dirty bluish purple. Stand with your back to the window, on a day when there is plenty of blue sky, cover one eye, hold the bottle close to the otler, and wait a minute or two. The purpose of that is to rest your eye. Then suddenly swing round, and look up through the bottle at the blue sky. You will see a patch-with some people it is oval-with myself it is round-a patch of a sort of purplishcrimson colour. The reason is because, as I said, the yellow spot does all the work of the eye, and consequently is in a state of chronic fatigue, and therefore, when it gets a holiday, enjors its holidar, and comes back from it not fatigued and biasé, but very much refreshed, just as do the people who perform the work of the world. When they return from a holidar, they are in good spirits, and not at all tired, and it is just so with the yellow spot. It is now capable of seeing the crimson light in the sky which, to the rest of the ere, is orerpowered by the blue. That is one way of demonstrating the existence of the Jellow spot. Sometimes at night, when you are trying to go to sleep, you may see floating about 
before you-floating away when you look at it, yet coming into view when least expected-a little group of bright stars, sometimes yellow, sometimes green, sometimes orange, floating about in the field of vision. Well, that is somehow or another, in a way that no physiologist has yet explained, connected with some functional activity of the rellow spot. Those are the principal ways of evidencing the existence of the yellow spot.

We now come to the theories of colour vision. One may say that the science of colour vision began with the discovery of Sir Isaac Newton, that light can be decomposed into rays of different frangibility and of different colour. Sir Isaac Newton said that these colours were in all seven-red, orange, yellow, green, blue, indigo, and violet. Later on, Wollaston taught that there are four colour sensations. He pointed out that the seven mentioned by Sir Isaac Newton differed somewhat in importance-in fact, Newton himself speaks of some of these colours appearing to be, as it were, transitional colours from one to another. Wollaston considered that yellow and orange were both transitional colours between red and green. He thought that blue was a separate colour, distinct from violet. But a man named Wunsch, who had made experiments by projecting upon the screen different colours produced by means of a prism, and comparing them with the seven colours of the spectrum, made the statement that if you mix together green and violet you produce the effect of blue. So it came to pass that with these data before him as regards colour-mixing, Thomas Young, about the year 1800, gathering together all that was known up to that time concerning colour vision, put it into the form known as "Young's Theory." That theory is based upon three fundamental facts. The first is that we possess a limited number of colour sensationsthree or four. The second is that, in addition to producing sensation, the light of any given col- 
our falling upon the eye temporarily diminishes its sensitiveness to that colour, and Thomas Young compared this process to muscular fatigue. The third fact on which his theory is based is that the sensation eroked by light of any given colour persists after that light has ceased to act, and only gradually dies away. In the year 1761 a very wonderful paper was written by a man named Scherfier, describing the phenomena of fatigue. He showed how, when the eye has been exposed to light of any given colour, it becomes less sensitive to that colour, so that if one looks afterwards at light containing several colours, then from those several colours there is subtracted light of the colour to which the eye has been exposed. For instance, supposing I expose the eye to red light, and afterwards look at white light, then the white light will appear to me no longer white, but white minus red, and if the four sensations are red, blue, green and violet, then white would appear, after exposing the ere to red light, to be a mixture of green, blue, and violet, which would look blue. If, on the other hand, I expose the eye to blue light, then I shall see all the colours that are left out of white after subtracting the blue from it. That is called the negative after-effect. The next discovery was made in 1786 , by Rohert Waring Darwin, one of the great family of Darwins, who showed that not only is the ere fatigued by being exposed to light of a given colour, but also that the sensation of that colour persists for some time after the light has been taken away. That is called the positive aftereffect. So that rou see Scherffer discovered the negative after-effect, and Darwin discovered the positive after-effect. Thomas Young's theory is based upon these facts, and Thomas Young supposes that we have in the eye nerves-or, as we slould say now, end-organs, because we now know that the nerve itself is not sensitive to light-we have in the eye end-organs belonging to the nerves, some of which respond specially 
to red, some specially to green, and some speeially to blue, or violet, or both. And Thomas Young, putting together all the experimental results of his contemporaries, was obliged to agree that although, for many reasons, blue seemed to be a separate colour-sensation, yet, in the absence of positive proof of this, he was bound to accept the experiments of Wunsch, and agree that there were three colour-sensationsred, green, and violet. And he was particular to note that although the red sensation is excited most strongly by red light, yet it is excited a little by blue light, and similarly green is excited a little by some of the red light, and a little by the violet. The violet also, he thought, might be excited slightly by the green, still less by the orange, and least of all by the red-but most of all by the violet; and according to Thomas Young, white light is due to the equal excitation of all these three sensations simultaneously.

About half a century after the time of Thomas Young, Helmholtz took up the subject independently, and arrived at a conclusion almost exactly the same. Maxwell also supposed that we have three colour-sensations, but considered them to be red, green, and blue. It seems extremely probable that Maxwell was partly violetblind, so that violet was a much less important colour to him than to Helmholtz, and that may have been why he gave preference to blue as a fundamental colour-sensation. Another scheme of colour-sensations was given by Konig. You notice his idea of red is that it begins about the $B$ line, that it reaches a maximum in the rellow, that it then comes down to a minimum between green and blue, and rises again to a second maximum as you get into the violet. $\mathrm{He}$ makes the green begin by the line $\mathrm{C}$, come to a maximum in the yellow, and fall to a minimum -to zero-before getting to the violet. Konig gives much more importance to blue as a colour than he does to either of the other two. It would 
seem that to him red was not so important a colour relatively as it is to many people.

While the next slide is exhibited, I would like to have the room as dark as it can be. There will be put upon the screen a bright red object, and I want you to look quite steadily at the little notch near the middle of it until you feel you cannot look any longer and must look at something else, and then you will see the effect I want you to see in a very striking manner. While you are looking I will tell you the reason why I show this. It is because some 25 or 30 years later than the time of Helmholtz, another theory was put forward by Hering. All the theories I have hitherto spoken of are varieties of one theory, but this of Hering is totally different. It is based upon the idea of contrast, and it says that we have in our eyes several chemical substances, of which the most important is the black-white substance. This, while it is being used up, causes the sensation of white, and while it is being secreted, the sensation of black. Then he says we have another substance, which gives the two sensations of red and of green-while it is being secreted it gives one sensation, while it is being used it gives the other. Similarly, a third substance is supposed to give the sensations of yellow and blue. All this while you have been using up the substance that gives the red sensation, and now $I$ am ready for the experiment. I push from behind the slide the red glass, and substitute colourless ground glass. The figure looks green to some and blue to others, and to a few pink. If we had had the room perfectly dark, it would have looked blue to all of you. The reason is, according to Hering, that we have been using up the red substance, and now it is being secreted again, giving the sensation of green. According to Young and Helmholtz, the reason is that you have been fatiguing the red sensation, and when you look afterwards at the white light, you see 
all the blue, all the green, and all the violet of it, but only a small proportion of the red.

When I went to Oxford, I found this theory of Hering was holding the field; the theory of Young and Helmholtz was considered refuted, and I should have believed the theory of Hering, as in duty bound, but for a curious little circumstance that happened when I was quite a young man, little more than a boy. I was amusing myself with a telescope, and, an eclipse having been announced for a few months later, was preparing my telescope to observe the sun, and was trying various pleces of red glass for the purpose. My red glass was not dark enough, but young people are not always very cautious, and I did examine the sun through it. I suppose the telescope magnified about 40 times, so that the sun more than filled the entire field of the eye-piece, and when I took my eye away I was horrified and astonished (it was out of doors), on looking at the flower-beds, to see the geraniums absolutely black. The leaves looked green, but the flowers appeared black.

The next slide I am going to show will illustrate what $I$ saw. It is a photograph of a rose, which I have coloured to represent the colour as it appeared to the normal eye-a bright pink. In the next slide, you will see how it appeared to me after I had looked through this telescope -a blue colour. The roses looked blue, the geraniums looked black, and the yellow flowers green, while the green leaves looked their ordinary colour. You may imagine that it was a very startling experience, and it led me to make some more experiments on the same lines. I tried different coloured lights. It was difficult to get coloured glass that would serve for green or blue, and the spectroscope showed that such colours were not pure. After a while I tried experiments with such prisms as I had in those days, and ascertained to my own satisfaction that it was possible temporarily to blind the eye to any one of the principal colours. Of 
course, only knowing the theory of Young, I thought it was all in complete accordance with that theory, and there was nothing more to be done. But when I came to Oxford, and learnt about the theory of Hering, it seemed advisable to repeat these experiments. I did so, with the aid of some of the apparatus presented to the University by the Dowager Duchess of Marlborough. Broadly speaking, this was the result. If you look at a very brilliant red light - the red of the spectrum anywhere about line $B$, and then look at a spectrum of moderate intensity, you will find that the violet, the blue, and the green, are perfectly visible, but the green runs right into the yellow up to about the $\mathrm{C}$ line, and there the spectrum ends. There is no yellow-it is all green. If rou blind the eye to green, the effect is that you can see blue and violet, and you can see red, but the red and the blue meet-there is no green between them. If you blind your eye to blue and violet, then the spectrum ends with green about halfway between $F$ and $G$. The effect, in the case of red blindness, lasts about 10 minutes; in the case of green blindness, about half an hour; while if you blind your eye with blue, the effect lasts fully an hour. In the case of violet, a very intense light is required, but the effect lasts fully two hours before it has wholly gone. Now suppose you blind your eye with yellow. light, what is the result? The red has gone, the green has gone; the spectrum begins near the B lines with blue, and goes on to violet. And although the effect of the blinding light may have been so strong that you cannot see to read a book, you can still see the other spectral colours to which you have not blinded yourself That is to say, when red-blind you can see violet, blue, and green; when green-blind, you can see red, blue and violet; when violet-and-blueblind, you can see the faintest red, as well as green. Each colour sensation is absolutely independent of the rest. 
This enabled me, to my own satisfaction, to settle one or two questions. Thomas Young had originally stated-following Wollaston-that there were four colour sensations-red, blue, green, and violet. Thomas Young gave up blue, because Wünsch said that green and violet mixed made blue. I was able to settle that question, because I found that you can blind yourself to violet without affecting the blue, and you can also blind yourself to green without affecting the blue, and therefore those two cannot produce blue. Then, again, Maxwell said that violet is produced by a mixture of blue and red. If that were so, then if you blind yourself to red it ought to reduce the violet and leave only the blue. But it does not-you are still able to see the violet.

The next slides will show what the spectrum looks like during the process of blinding the eye. The first represents the spectrum from the $\mathbf{E}$ line to $b$. Imagine that it is a spectrum of very wide dispersion, and that you have got the full strength of the sunlight on it, so that it is almost painfully bright to look at. As you look at it it begins to get white. That is the stage at which most experimenters have stopped. But if you keep on looking at it, the colour comes in again, and when the green is entirely gone, the red and blue meet. And if you look towards the blue side of the spectroscope the red appears to encroach upon it, while if you look towards the red side, then the blue appears to surge up and go over towards the red. If, on the other hand, you try that part of the spectrum near the $\mathbf{F}$ line, where the blue and green meet, you may look at it as long as you like, but it will never change; you cannot get any other colours than those two. Now, suppose you turn to the blue part of the spectrum, and that you look at it steadily till your eyes ache. It will first lose colour and become white, then the green will begin to come in at one side, and the violet at the other, until they meet in the middle 
"of what was the blue. The explanation I give is that the colour which is most strongly excited is most powerfully fatigued, and it is possible to become blind to that colour without affecting the others. I think that these experiments are completely contrary to the theorr of Hering, and that ther corroborate the original theory of Thomas Young. I believe that this Society is interested in the work of Thomas Young, and I am very pleased to say that in my opinion his theory was not only the true theorr, but was even more true than he imagined-that is to say, his original theory of four colours, red, green, blue, and violet (which he gave up in consequence of Winsch's experiments) is the true one.

When I first published these experiments, the objection was raised that it is really a pathological condition which I produced by this intensel brilliant light, and that therefore it could not be said that the experiments were perfectly fair. My answer was that you can perform all these experiments with moonlight, the only difference being that you must stay in darkness long enough to allow the effect of previous darlight, or artificial light, to subside completely from your eye.

Now, with regard to "colour blindness." I have made use of this method for testing colour-sensations. I do not expose the eyes of my victims to the intense light that I used in my own case-and let me say here that I do not recommend that any of you should do this. I repeated the experiments a good many times with impunity, but the last time I did so, for the purpose of the illustrations that accompany my paper in the Philosophical Transactions, I found that after the experiment there was a great triangular patch of total redblindiness on the left-hand side of the field of one eye, and that condition of things lasted for very nearly two jears. It has quite died out now, and the eye is normal again, but Sir 
George Stokes told me that his eye was permanently damaged by a somewhat similar experiment, and the oculist who examined his eye informed me that you could see the effect on the retina of the burning of the intense light to which it had been exposed. So be cautious, and do not let me incite any of you to perform these experiments without fully realising that by so doing you will risk your eyesight. But I use the same method for testing people's eyesight in this way. Colours such as you look at habitually do produce a very considerable and measurable amount of colour-blindness. For instance, if you attend a cricket match, you will probably be more than three parts greenblind when you come in afterwards, as the effect of looking at the green grass. You may make yourself quite half red-blind if you sit in a room papered with crimson paper, in the sunlight. I use these facts in testing people. I make them look at the red of the spectrum, using a quite moderate intensity, and, after 30 seconds' exposure to that colour, they turn. the screws of the spectroscope so as to traverse the spectrum across the field, and stop where the colour changes from red to green. Then I let them look at the green, with the ordinary intensity you would use for examining the spectrum. When they have looked for 30 seconds, I make them find where blue begins, and when they have looked at blue for 30 seconds I let them find violet. Then I make them determine how far they can trace the violet to the end of the spectrum. Having done that, I make them look at the violet for 30 seconds, and find where the blue begins. After exposure to blue they find where green begins, and after looking at green they seek the beginning of red. On comparing the results, it is found that they have called the same part of the spectrum red or green, according as they have been looking at green or red. In other words, the red and the green sensations overlap. So do 
the blue and the green, and also the violet and the blue. By this method the extent of the overlap can be measured, and the middle point of each overlap may be taken as the natural boundary between the adjacent colour sensations. To the normal sighted these boundaries occur about $D$ for green and red, near $F$ for green and blue, and about $G$ for blue and violet.

A man who is red-blind will not be able to see very far into the red, and he will find no change at $\mathrm{D}$-there may be a change of in. tensity, but not a change of quality, though he will very likely tell you there is a change if he has been taught to use the spectroscope, and will say that one part is red and the other yellow or green. $\mathrm{By}$ the method I have described, his red-blindness may be detected. Let him point out, without previously fatiguing the eye, where what he calls "yellow" begins. Then, after fatiguing him with red light, let him find the same "yellow" or green, or whatever he calls it. If he really possesses a sensation of red as well as green, he will find the change of colour nearer to the red, but if he possesses no red sensation, the change will appear to have moved farther into the green, because it is not caused by a different colour-sensation, but is simply the brighter part of the same colour, and it mores further away because he is fatigued. A man who is colour-blind to green will find no change of colour at $D$, but a very sudden change at $b$ in the middle of the green where normal people see no change, or very little. It is necessary to remember that in dealing with a colour-blind man, you are dealing with a man who talks another language. I have some examples here of skeins of wool, which have been called a good match by the colour blind: One is bright red matched with dark green. Another is violet, matched with a sort of reddish-brown. For the purpose of detecting colour-blindness, these skeins of 
wool are the quickest and the best, but they need some training in their use. Just as the doctor learns how to diagnose diseases, so you have to learn to diagnose cases of colour-blindness-you have to watch the person who is doing it to see if he is really making mistakes, or if he is trying to deceive you. Remember that there are two classes of persons who come to have their sight tested-there are those who want not to be found out colour-blind, and there are those who, lnowing themselves to be colour-blind, are interested scientifically in it. Now, for the second class of people the spectroscope test is the surest and quickest you can have, but for the first class of people I think a good selection of wool skeins is far the best. There should be at least two samples of each colour, and you want a great many different delicate tints as well as the brighter ones. The slide I am now showing is a very curious case-a piece of green glass and a piece of purple glass, given to me by a person who was green-blind, and who said that those two colours were exactly alike. Green-blindness is very much rarer than red-blindness. On an average about 4 per cent. of men are colourblind, and only about .4 per cent of women.

Very occasionally one meets with people in whom the blue colour-sensation is completely absent. In a very great many people it is largely absent, and I believe that is one reason why so many writers have said that there is no separate sensation of blue. I have come across one person in whom the violet sensation is completely absent. In the spectrum of the electric arc, there is a group of lines between the blue and the extreme violet fairly close together. In one of the cases I examined, the person could see all the lines in the group up to $\lambda 4160$, whereas I could see lines beyond as far as $H$ and $K$. To him the spectrum ended absolutely and completely at that point, and I found by other measurements that 
in his case the sensation of violet was completely lacking, while he had those of red, green, and blue.

There is only one other thing I have to mention. The relative sensitiveness of the eye to different colours is continually varying to an enormous extent. I told you how, if you had been playing cricket, you would find yourself almost completely green-blind because of the green of the grass. I find that it is necessary to stay at least two hours in darkness in order that the eye may recover completely from all the effects of previous light, and even that, in many cases, will not be sufficient. Two hours is the shortest period in which it is possible to get rid of all the after-images. I found, by actual experiment, that the eye, when it is completely rested, is from 15 to 20 times as sensitive to red as it was before-the red sensation increases in power 15 to 20 times, but the blue sensation increases in power from 1,000 to 1,100 times, so that you are able to see light 1,000 times as weak after you have been two hours in darkness, as jou can in bright daylight. That means that when you go out of the bright light into a room which is partially dark, your estimate of colours alters rapidly and very considerably, so that a colour which appeared to be bright red may, on going into a dark room, seem perfectly white. Let me conclude by suggesting this very simple experiment. Some bright, sunshiny day, when you are out in your garden, pluck a petal from a scarlet geranium, and lay it upon your hat, which for that purpose must be a black one. Carry it with you into the house, and go into the darkest corner you can find-into your cellar. As you get into the gloom, looking at this brilliant scarlet petal, it will change from scarlet to orange, from orange to yellow, and the last you see of it it will be quite white. That is simply becruse the sensitiveness of your eve alters to different colours in different 


\section{3}

proportions, and the very small amount of blue, green, and violet reflected by the scarlet geranium petal is sufficient, as the eye becomes more sensitive, to mix with the red and to pro duce white.

I feel that I have taken up a great deal more time than I ought, bit still I have not by any means exhausted the subject, and my excuse must be that there is a very great deal to be said upon it. 